\title{
Australia's NBN: Come Hell or High Water
}

\author{
Kevin Morgan ${ }^{1}$
}

Are there projects of such self-evident value that they ought to be exempt from even the most rudimentary cost-benefit analysis? Seemingly so, according to the former Finance Minister Lindsay Tanner, as long as it's the National Broadband Network (NBN). In May 2009, a month after Kevin Rudd had announced the \$43 billion project, when asked about the absence of a cost-benefit analysis (CBA), Tanner said: 'We had to make the clear decision that said this is the outcome we are going to achieve come hell or high water because it is of fundamental importance to the future of the Australian economy' (quoted in Martin 2010).

A year later, Tanner remained unmoved by Opposition calls for a CBA and he dismissed such analysis as subjective because 'cost-benefit analyses of the orthodox kind are basically captives to the assumptions you feed in' (Martin 2010).

Stephen Conroy, the Broadband Minister, was similarly dismissive. When pressed in May 2009 about the lack of a CBA, he told opposition spokesman Senator Nick Minchin, 'As I have repeatedly stated, this is an election commitment and we intend to deliver it.' (Senate Hansard 2009). The election commitment had actually been a $\$ 4.7$ billion upgrade of the copper network which also had not been subject to a CBA. Clearly, for Conroy, election promises don't have to be evaluated, even when they have morphed from a $\$ 4.7$ billion upgrade using 'fibre to the node technology' (FTTN) into a $\$ 43$ billion 'fibre to the home' (FTTH) network.

Conroy's lack of interest was perhaps understandable. Had the \$43 billion project been subject to a CBA, his failed $\$ 4.7$ billion policy may have come under renewed scrutiny. Under that initial policy, the government had tendered out the right to upgrade the Telstra copper network. Given that Telstra had not agreed that anyone else could upgrade its network and the government had not offered compensation to secure that right, the tender collapsed when Telstra was dismissed from the bidding in late 2008. No doubt FTTN, the most commonly deployed technology to deliver high-speed broadband, which uses fibre to a street corner cabinet, would have been revisited in a CBA.

1 kevinlmorgan@bigpond.com 
Tanner's readiness to dismiss the need for a CBA was, though, less understandable. The Department of Finance is the custodian of CBA practice and has a lead role in reviewing projects. Finance maintains the Handbook of Cost-Benefit Analysis that governs the evaluation of new projects and its Office of Best Regulatory Practice sets out the processes by which new legislation should be evaluated, including cost-benefit analysis.

Also the project had obvious implications for the budget. Under the Public Private Partnership model that was initially proposed, the Commonwealth's 50 per cent commitment would have been $\$ 11$ billion in equity and a guarantee on $\$ 10.5$ billion in debt.

Nor can Tanner's lack of interest be reconciled with his complaints about the lack of serious policy debate. Mr Tanner believes that politics has been dumbed down and that few are interested in detailed policy debates. On releasing his book Sideshow: Dumbing Down Democracy in April 2011, Tanner said: 'I would always try to put the focus on the merits of the issue ... but at times I felt overwhelmed. I sometimes felt like I was talking a foreign language' (Australian Broadcasting Corporation 2011).

In relation to the NBN, whatever language he was speaking it wasn't the language of CBAs. Indeed, there was an unspoken subtext which Tanner acknowledged in 2011. In his reflections on his time as a 'reformist minister', Tanner said the NBN was really about 'getting the market structure right', an objective he and Broadband Minister Stephen Conroy had 'pursued relentlessly over seven years' (Tanner 2011). That meant the structural separation of Telstra. The PM, Julia Gillard, claimed this was the 'Holy Grail' of telecommunications reform which would lead to significant benefits from heightened competition and finally deliver on Professor Fred Hilmer's 1993 competition policy reforms. ${ }^{2}$ Although the direct costs of separation are known - Telstra is to be paid \$11 billion in compensation - the benefits have not been quantified, as the policy was not subjected to a CBA.

Professor Hilmer took issue with the Prime Minister's claim saying 'his committee had taken a cynical attitude towards claims that utilities involved natural monopoly infrastructure elements that needed to be separated from more competitive retail activities' (see The Australian, 7 December 2010). That view reflects the international consensus that the costs of structural separation potentially outweigh the benefits. Consequently, no regulator has enforced structural separation, meaning that like the NBN there is no international precedent for separation. That uniqueness alone was good reason to test the benefits of separation through a CBA.

2 Transcript of joint press conference 'Prime Minister Broadband Minister', Sydney, 29 March 2012. 
The resolve to secure separation and create a wholesale-only NBN was such that the government wasn't merely ignoring opposition calls for a CBA: it was ignoring its own policy on infrastructure. Infrastructure Australia had been created in April 2008 to, amongst other functions, 'evaluate proposals for investment in, or enhancements to, nationally significant infrastructure'. ${ }^{3}$ In its first report in December 2008 it said it had developed 'a new approach to decision making [that] uses a robust framework' (Infrastructure Australia 2008). The framework includes seven stages for the evaluation of projects, and at the sixth stage projects are to be subject to a CBA.

Although neither the initial $\$ 4.7$ billion FTTN network nor the $\$ 43$ billion NBN had been identified and prioritised for funding by Infrastructure Australia, there was a clear intent that all major projects, including communications projects, should be considered by that body. The NBN had been identified by Infrastructure Australia as one of its seven infrastructure 'themes.' But a key brief for Infrastructure Australia was also to ensure the better use of existing infrastructure 'to solve problems without the need for investment in additional capacity' (Infrastructure Australia 2009), and that raised the spectre that upgrading the existing network with FTTN might be revisited had they been consulted.

In failing to allow Infrastructure Australia to evaluate the NBN, the government wasn't just denying its own policy intent. It went counter to the provisions of the Nation Building Funds Act 2008, given that the $\$ 2.5$ billion seed funding for the NBN was held in the Building Australia Fund.

Under Section 52 of the Nation Building Funds Act, the Minister for Finance may not authorise a payment from the Building Australia Fund unless the Communications Minister 'has recommended the authorisation of the payment'. But under Section 52(5) the Communications Minister must not make a recommendation 'unless Infrastructure Australia has advised under section 117 that the payment satisfies the relevant BAF evaluation criteria'. The evaluation criteria require that 'Proposals should demonstrate, through a cost-benefit analysis, that the proposal represents good value for money.'

In summary, as the Senate Select Committee on the NBN noted in its third report in November 2009, the government was refusing to comply with its own legislative requirements (Senate Select Committee 2009). The report provides a concise account of the government's failure to observe proper process in relation to the evaluation of the NBN.

The Committee also provided the only major public forum in which the need for and lack of a CBA was debated. It drew significant contributions from the

3 Infrastructure Australia Act 2008, Section 5, 'Functions'. 
Productivity Commission, the Business Council of Australia and from Henry Ergas and Mark Harrison, who had undertaken a CBA of the NBN as part of a 2009 Productivity Commission roundtable on evidence-based policy.

In its submission to the committee, the Productivity Commission noted the uncertainties that surrounded the NBN such as the evolution of technologies and consumer demand' (Senate Select Committee 2009: Chapter 6) that would make it difficult to undertake a CBA. They suggested that some of the uncertainty could be lessened, by running trials. This would have given some hard data on rollout costs, on demand and on consumers' 'willingness to pay'.

Given that NBN Co. was committed to building five 'first release [trial] sites' in early 2010 and that a limited rollout was already under way in Tasmania, the suggestion had considerable merit. The mainland first-release sites and Tasmanian rollout would have provided a wealth of data. They embraced a wide range of geotypes and a broad social and economic spectrum. It was also obvious from NBN Co.'s first corporate plan that the volume rollout would not begin until 2011, when the 14000 homes to be served in the first-release sites were completed (NBN Co. 2010). The Productivity Commission's suggestion and NBN Co.'s timetable were clearly not in conflict.

Nevertheless, the Productivity Commission's proposal was ignored, as was its call that the \$25 million McKinsey-led NBN implementation study, which had commenced in mid-2009, should include a cost-benefit analysis. Similarly the Business Council's calls for a CBA were ignored, with the government members on the committee claiming that it would lead to prolonged delays in the rollout.

But whilst the government's response to the Productivity Commission and Business Council was marked by a lack of interest, the response to the ErgasHarrison study was less restrained. Their findings suggested the costs of the allfibre NBN would outweigh the benefits by $\$ 14-20$ billion and lead to $\$ 200$-plus a month retail pricing for high-speed services (Senate Select Committee 2009: Chapter 6). Their findings had been based on a counterfactual that may have touched a raw nerve with the Broadband Minister Stephen Conroy as it was predicated on FTTN, which in urban areas could comfortably deliver speeds of $40 \mathrm{Mbs}$. The study was not merely dismissed but was the subject of a highly personal attack by Conroy on Ergas in an estimates hearing in May 2010.

Ergas and Harrison had questioned the NBN in the context of low demand internationally for FTTH services and had made the quite reasonable assumption that as a government business enterprise the NBN would be required to earn a commercial rate of return. But as they demonstrated, a commercial rate of return would demand NBN pricing that would translate into retail prices that consumers might not be willing to pay. 
Consequently, to ensure the NBN's prices 'met the market' ${ }^{4}$ and were comparable to existing prices, the Implementation Study found that the NBN could be commercially viable, with an internal rate of return of 7 per cent, marginally above the long-term bond rate. In a subsequent appearance before the Select Committee, Ergas pointed out that the government had never explained why a return just above the long-term bond rate was acceptable. Indeed, treating the NBN in this way wound back GBE reform which had seen the Hawke/Keating government raise the interest rate on Telecom Australia's debt from the bond rate to a commercial 13 per cent. There was, though, considerable benefit from deeming the NBN to be 'commercial'. It kept equity injections off-budget and exempted the NBN from scrutiny by the Public Works Committee. The downside was that a low rate of return meant the PPP funding model was abandoned, exposing taxpayers to a liability of $\$ 27.5$ billion in equity and guarantees on some $\$ 13$ billion in debt.

The government holds out the McKinsey implementation study and NBN Co.'s subsequent corporate plans as vindication of the NBN. But neither the McKinsey study nor the two iterations of the NBN corporate plan offer the insights that a CBA could offer. The McKinsey study stressed that it had 'not undertaken a cost benefit analysis of the macro economic and social benefits that would result from the implementation' (McKinsey/KPMG 2010). The study did, however, examine the costs of building the network and found that it could be built for $\$ 42.8$ billion, only $\$ 200$ million under the initial estimate. Yet despite being more than 500 pages long, the study doesn't contain any spread sheets or detailed breakdown of costs that would allow an independent observer to establish whether the capital cost is reasonable. The study is remarkably vague, even on the size of the NBN network. It merely notes that around 250000 kilometres of fibre will have to be deployed.

Nor can the NBN Co.'s corporate plan, which does not assess benefits, be accepted even as an objective and reliable assessment of costs or revenues. Only 9 per cent of the rollout targets set for mid-2012 under the first plan released in December 2010 were achieved. This failure was addressed by issuing a revised plan in August 2012. The new plan revealed capital costs had been underestimated by $\$ 2.8$ billion, or 14 per cent, because the network would actually need to be 25 000 kilometres longer.

That error suggests that estimating the NBN's costs is a work in progress and that the initial cost estimate of $\$ 43$ billon may not have stood up to scrutiny. As Treasury and Finance stated in estimates hearings in May 2009, the initial

4 In a brief to consultants assisting NBN Co. on its Special Access Undertaking, NBN Co. noted that prices had been 'set to meet the market' (Synergies Economic Consulting 'Advice on NBN Co. Ltd's Special Access Undertaking': 8). 
estimate was not the product of a CBA, although Finance did undertake some analysis of costs, noting that 'Our costing exercise was entirely related to the cost of building or acquiring a network. It was not a business study or a cost-benefit study or a business case analysis' (Senate Select Committee 2009: Chapter 6).

It appears that the costs considered by Finance were first generated by the expert group that considered the FTTN bids in late 2008. One member of the panel confided privately that once the demise of the FTTN tender became obvious, they turned their attention to FTTH and extrapolated costs on fibre deployment from a 2008 British report to the Australian market. ${ }^{5}$ Given the significant differences between UK and Australian geography, use of the UK estimates may have significantly underestimated FTTH costs for Australia.

The fragility and uncertain origins of that initial cost estimate may in large part explain why the NBN has not been subject to a cost-benefit analysis. Technology experts who advised the government on the original FTTN policy believe FTTH capital costs lie between $\$ 60-\$ 80$ billion. ${ }^{6}$ Also, despite claiming that the NBN will boost business productivity and transform the health and education sectors, these sectors are already well served with fibre and highspeed broadband. More significantly, although there are many studies that demonstrate the benefits of broadband, as Howell and Grimes have noted there are none that demonstrate that very-high-speed broadband, so-called thirdgeneration broadband, yields significantly greater benefits than current secondgeneration broadband (Howel and Grimes 2010). A CBA might have called into question many of the government's claims about the NBN's benefits, which appear to lie in as-yet-unknown applications. ${ }^{7}$

Although the government maintains that calls for a CBA are politically motivated, in refusing to undertake one they have ignored expert and non-partisan advice from, amongst others, the Productivity Commission, the Business Council and two leading academic experts on cost-benefits analysis. Given that Lindsay Tanner recently described the NBN as 'an improvised response to an unexpected situation' (see The Age, 26 September 2012) the unwillingness to subject the NBN to a CBA has been a political imperative for the government, which refuses to expose a hastily-thought-out policy to proper scrutiny. And in the absence of any international precedent for either a national FTTH network or structural separation, a CBA would have been the only way to establish the evidence base which Kevin Rudd had said was integral to framing policy.

\footnotetext{
5 Broadband Stakeholders Group, 'The costs of deploying fibre-based next generation broadband infrastructure', 8 September 2008.

6 'Gibson Quai AAS founder predicts NBN cost as high as A\$80 billion', Commsday, 16 May 2011.

7 The Treasurer Wayne Swan commented on launching an NBN trial site in mid-2011 that the NBN was being built 'So that we can tap the unknown possibilities of the future, the known possibilities and the unknown possibilities', The Australian, 29 July 2011.
} 


\section{References}

Australian Broadcasting Corporation 2011, 7.30 transcript, Leigh Sales and Hon. Lindsay Tanner, 28 April 2011.

Howell, B. and Grimes, A. 2010, 'Feeding a Need for Speed or Funding - a Fibre "Arms Race"? Productivity Questions for FTTH Network Financiers', New Zealand Institute for the Study of Competition and Regulation \& Victoria University of Wellington, April 2010.

Infrastructure Australia 2008, 'A Report to the Council of Australian Governments', December 2008.

2009, ‘National Infrastructure Priorities', May 2009.

Martin, I. 2010, 'The promised land', Telecommunications Journal of Australia 60(2), Monash University ePress.

McKinsey/KPMG 2010, 'NBN Implementation Study'.

NBN Co. 2010, 'NBN Corporate Plan 2010-2013'.

Senate Hansard 2009, 'Senate Standing Committee on Environment Communications and the Arts' Estimates, 26 May 2009.

Tanner, Lindsay 2011, 'A portent of things to come: lessons from a reforming minister' in Lindquist, Evert A., Vincent, Sam and Wanna, John (eds), Delivering Policy Reform: Anchoring Significant Reforms in Turbulent Times, ANU E Press. 